\title{
Prospective Impact of Technologically Enhanced Language Learning On Learner Achievement in Reading Skills-A Case Study of Nakuru County
}

\author{
Rodney A. Asilla ${ }^{1}$, Prof. Mark Okere ${ }^{2}$, Dr. Joel K. Ng'eno ${ }^{3}$, \\ ${ }^{I}$ Department of Curriculum, Instruction and Educational Management, Egerton University, Kenya. \\ ${ }^{2}$ Dept. of Curriculum, Instruction and Educational Management, Egerton University, Kenya. \\ ${ }^{3}$ Dept. of Curriculum, Instruction and Educational Management, Egerton University, Kenya.
}

\begin{abstract}
This study was conceived to help determine the prospective impact of introduction of ICT on achievement in English language reading skills in Kenyan secondary schools. The study was conducted among Form 2 students in four selected secondary schools in Nakuru County. The study used Randomized Control Trial (RCT)approach, through the pre-test-post-test method. Data were collected in two stages, first at the pretest stage before the intervention, followed by the post-test stage after the Reliability of the instruments was estimated using Cronbach's alpha; where a correlation co-efficient of $\geq 0.81$ was achieved. Sampling for the study was through the multi-stage technique, with purposive sampling first to identify schools with desired characteristics, followed by random selection to select schools for the study. The potential impact of ICT on students' achievement was estimated using Difference in Differences (DD) technique, $t$-tests and effect size to test for differences in the means of the scores of the two groups. Effect size was estimated using Cohen's criteria. Testing of the instruments was done through conduction of pilot studies in two schools, one as a test and the other as a control, to determine the reliability of the instruments for the study. The results of this study indicated that there was significant difference in achievement in reading skills in favour of the experimental group. It is, therefore, recommended that the government significantly improves the current classroom ICT situation in Kenyan classrooms in order that learners may fully benefit from the education they receive.
\end{abstract}

\section{Introduction}

The government of Kenya, in its Jubilee Party Manifesto, and in The National ICT Masterplan introduced in 2014, focused on improving the learning experience of both primary and secondary school students through the introduction of laptops in two stages; first at the primary level, then the secondary level. This move has been informed by global trends, government policy and the Vision 2030 development plan.

Global trends include the Millennium Development Goals (MDGs), among which is a provision for universal achievement of primary education; the Education For All (EFA) project, which is focused on the provision of quality education for all; and the United Nations Literacy Decade (UNLD), which also places emphasis on the quality of learning, both what students learn and how they learn it (UNESCO, 2008).

In policy implementation, one issue that was highlighted on the agenda on the manifesto of the current government was the implementation of a new technologically-enhanced learning programme through the introduction of laptops for primary schools. While the programme is yet to fully take off at the time of the study, it is still high on the government's agenda, and has been piloted (Gacicio, 2014).

This is also supported by the enactment of the Kenya Institute of Curriculum Development (KICD) Act of 2013; and the adoption of the Vision 2030 development plan. The KICD was mandated with the responsibility of being in charge of curriculum development. One of its key responsibilities, as stated in the act, is to 'develop, disseminate and transmit programmes and curriculum support materials through mass media, electronic learning, distance learning and any other mode of delivering education and training programmes and materials'.

The Vision 2030 is a development plan that is set to transform Kenya into a middle-income country with a high quality of life by the year 2030. To this end, the government identified three key pillars; social, economic and political, that would support the achievement of the goals and objectives laid out in the Vision 2030. Education and training is a fundamental part of the social pillar. Under education and training, Kenya will provide a globally competitive and quality education, training and research (Republic of Kenya, 2012).

Technologically enhanced learning has been greatly employed in other countries. In Asia, for example, the use of technology in teaching and learning has been of great importance, specifically in the teaching of foreign languages such as English in China (Hu, 2002). Hussain et al. (2010) conducted a study on the impact of ICT in English language learning in Pakistan and found that the learners performed better when they were instructed in a technology based learning environment, and that technology was central to the learners' 
development of their abilities of knowledge, comprehension and application. In the United States, studies have shown that the role of technology in learning has also been directly linked to learner achievement.

In Africa, and more specifically in Kenya, the use of such technology has not been fully embraced, as a result of various challenges that face implementation of such programmes (Evoh, 2007). This has contributed to a lack of information on the potential impact of technologically enhance learning on learner achievement, and more specifically, technologically enhanced language learning (TELL) in English language. This, therefore, creates a need to fill this knowledge gap.

\section{Literature Review}

The history of TELL has grown from the 1960s and 1970s with the use of language labs, in which there were booths, each providing a cassette deck, and accompanying microphone and headphone. Teachers monitored their students' interactions by using a central control panel (Zamani, 2014). The basic premise behind this technology was that if verbal behaviour was modelled, and then reinforced, students would quickly learn the language in question (Alexander, 2007).Presently, there are a variety of computer applications available including vocabulary, grammar, and pronunciation tutors, spell checkers, electronic workbooks, writing and reading programs, as well as various authoring packages to allow instructors to create their own exercises to supplement existing language courses (Gündüz, 2005).

As concerning the effectiveness of TELL on learner achievement, multiple studies have confirmed that TELL indeed enhances learner achievement in language skills, both input and output language skills. Mdlongwa (2009) lists the perceived benefits for the student as: increased motivation; increased active participation and creativity; improvement in knowledge and skills; increased responsibility and self-esteem; and increased collaboration. Carr et al., (2011) found that increased use of TELL in language learning was helpful in increasing the students' confidence in acquiring speaking skills for the new language, through increased interactive speaking and writing exercises that the introduction of ICT offered.Balanskat and Blamire (2006) point out that there was significant evidence of the benefits and advantages that the use of TELL had on students as; increased student motivation and therefore, enhancement of the student's personal commitment and engagement; enhanced independent learning.Ramirez (2012) also notes that the use of TELL contributes to enhanced collaboration and communication among the students, through the use of communication technologies; and lastly, there would be an improvement in student attainment and outcomes.

\section{Purpose of the Study}

The purpose of this study was to conduct a prospective impact evaluation of the implementation of technologically enhanced learning on learner achievement in English language reading skills.

\section{Hypothesis}

The study tested the following hypothesis; There is no statistically significant difference in achievement in English language reading skills between students taught using technologically enhanced language learning and those not taught using technologically enhanced language learning.

\section{Methodology}

The study employed a case study of Nakuru County, employing an experimental template. An experimental template design refers to how participants are allocated to the different conditions in an experiment (McLeod, 2007). For this study, the type of experimental template used was the Randomized Control Trial (RCT), specifically through the use of pre-test-post-test method. It was appropriate because the aim was to compare the achievements of the experimental groups with those of the control groups. The research design specifically employed the dynamic comparison. Gerring (2007) defines a dynamic comparison as one where the independent variable is exposed to manipulated change, and where one case, the control group, is not allocated treatment. The dynamic comparison was also appropriate because it allowed for observation on both the temporal and spatial dimensions, and involves selection of two groups similar in each respect for both the control and test groups. In the temporal dimension, impact was observed directly when an intervention occurs, while in the spatial variation, observation was made where two phenomena are similar enough to be understood as cases of the same thing, with the only difference between them being the introduction of a treatment for one case, and lack of a treatment for the other (Gerring, 2007).

Data collection was through the use of pre-test-post-test method. This was through giving English language writing and reading tests to both the test and control groups before and after the intervention, to determine the impact of the intervention on learner reading and writing skills. A questionnaire was administered at the end of the study to determine the impact of technologically enhanced language learning on learner motivation. 
The data were analysed using both quantitative and qualitative methods. Quantitative data collected from the tests involved the use of Difference-in-difference (DD) technique, to determine the effect of the use of technology in language learning. The data analysis also used t-tests, an inferential statistical procedure used to determine if there was any significant difference between the means of the two groups, the test group and the control group. Hypotheses were tested at $5 \%$ level of significance using the SPSS software. The measure of in the difference between the effects of the two independent variables on learner achievement was determined through computation of the effect size, using the Cohen's d formula.

\section{Results And Discussion}

\section{Difference in Difference Analysis of Impact of ICT on learner achievement in reading skills}

The study first undertook a difference in difference analysis to determine the potential impact of ICT on learner achievement in reading skills. This was done through giving a similar reading test to both the experimental and control groups at the beginning of the study, known as the pre-test. After giving the test, the scores achieved by the learners were recorded in both the test and control schools, and the average scores for each group determined. The two groups were then re-tested with the same concepts on reading skills as they had been tested before, with a similar reading test given to both the test and control groups, known as the post-test. The average performance for both the reading and control groups is represented in the Table 1 .

Table 1 Average performance of both Test and Control School groups in Pre-test and Post-test Reading Skills

\begin{tabular}{|l|l|l|l|}
\hline & Reading Pre-test Average mean & Use of ICT & Reading Post-test Average Mean \\
\hline Test School group & $34.5111 \%$ & Yes & $48.6815 \%$ \\
\hline Control School group & $16.8235 \%$ & No & $30.2857 \%$. \\
\hline
\end{tabular}

The average difference-in-difference score was calculated by finding the difference in performance in the test group, and subtracting the difference in performance in the control group school. This meant subtracting each group's average pre-test score from its average post-test score, and finding the difference between the two differences attained. The procedure was as indicated in the Table 2.

Table 2 Procedure for Calculation of Average Reading Skills Difference-in-Differences Score between Test School Group and Control School group

\begin{tabular}{|l|l|l|}
\hline & Test School Group & Control School Group \\
\hline Average Post-test reading score (\%) & 48.6815 & 30.2857 \\
\hline Average Pre-test reading score (\%) & 34.5111 & 16.8235 \\
\hline Difference (\%) & 14.1704 & 13.4622 \\
\hline
\end{tabular}

The test school group attained a pre-post difference of $14.1704 \%$, while the control school group attained a pre-post difference of $13.4622 \%$. With both differences attained, it was now possible to determine the average difference-in-differences score, which was done by subtracting the pre-post difference of the control group from the pre-post difference of the test group. The result was an average difference-in-differences value of $0.7082 \%$.

This result pointed to the fact that the experimental group performed better than the control group. The difference-in-differences analysis performed above indicated that there was a significant positive difference in impact of ICT on reading skills in favour of those who used ICT in learning when compared to those who only used the traditional textbook method. However, this did not give the significance of the difference, which was therefore determined by use of the independent t-test.

\section{Independent T-Test Analysis of significance in difference in achievement in reading skills}

In order to determine the significance of the difference in achievement of both the test school groups and the control groups, an independent t-test was carried out on the hypothesis; There is no statistically significant difference in achievement in English language writing skills between students taught using ICT and those not taught using ICT. The independent t-test is a statistical procedure that is carried out with the aim of finding the significance in difference between the average scores of two groups.

The hypothesis, There is no statistically significant difference in achievement in English language writing skills between students taught using ICT and those not taught using ICT, was tested for significance at 0.05 level of significance, also known as the 5\% significance level. The values attained after the independent $\mathrm{t}-$ test procedure are as shown in the tables below; 
Table 3 Descriptive Statistics of t-test analysis for reading skills

\begin{tabular}{|l|l|l|l|l|l|}
\hline & school type & $\mathrm{N}$ & Mean & Std. Deviation & Std. Error Mean \\
\hline \multirow{2}{*}{ posttest reading } & test & 135 & 48.6815 & 11.34970 & .97683 \\
\cline { 2 - 6 } & control & 119 & 30.2857 & 11.48776 & 1.05308 \\
\hline
\end{tabular}

Table 4 Output of Independent t-test for measuring significance in difference in achievement in reading skills

\begin{tabular}{|c|c|c|c|c|c|c|c|c|c|c|}
\hline & & \multicolumn{2}{|c|}{$\begin{array}{l}\text { Levene's Test for } \\
\text { Equality of } \\
\text { Variances }\end{array}$} & \multicolumn{7}{|c|}{ t-test for Equality of Means } \\
\hline & & & & & & & & & $\begin{array}{l}95 \% \\
\text { Interval } \\
\text { Difference }\end{array}$ & $\begin{array}{l}\text { Confidence } \\
\text { of the }\end{array}$ \\
\hline & $\begin{array}{l}\text { Equal } \\
\text { variances }\end{array}$ & $\mathrm{F}$ & Sig. & $\mathrm{t}$ & df & $\begin{array}{l}\text { Sig. (2- } \\
\text { tailed) }\end{array}$ & Mean Diff. & $\begin{array}{l}\text { Std. } \\
\text { Error } \\
\text { Diff. }\end{array}$ & Lower & Upper \\
\hline \multirow{2}{*}{$\begin{array}{l}\text { posttest } \\
\text { reading }\end{array}$} & assumed & 4.364 & .038 & 12.817 & 252 & .000 & 18.39577 & 1.43528 & 15.56910 & 21.22243 \\
\hline & $\begin{array}{l}\text { Not } \\
\text { assumed }\end{array}$ & & & 12.807 & 247.237 & .000 & 18.39577 & 1.43637 & 15.56668 & 21.22486 \\
\hline
\end{tabular}

Table 3 provides the descriptive data for the study, which indicates the number of respondents for each of the groups. The test sample had a population of 135 , and the control sample had a population of 119 . Table 4 provides the results of the actual t-test, with the values of significance.

The independent $\mathrm{t}$-test produced a value of $\mathrm{t}=-12.807$, with a $\mathrm{p}$-value of $\mathrm{p}=.000$; which indicated that there was a significance in difference in performance between the students who used ICT in learning reading skills and those who did not use ICT, as indicated by the $p$ value.

The score of the $p$-value was at $p=.000$, which was less than 0.05 . There was, therefore, enough evidence to reject the null hypothesis that; there is no statistically significant difference in achievement in English language reading skills between students taught using ICT and those not taught using ICT, and accept the alternate hypothesis that; there is a statistically significant difference in achievement in English language reading skills between students taught using ICT and those not taught using ICT. While the t-test gave a measure of significance of the difference in achievement between the group that were taught English language reading skills using ICT and those who were not, it did not give a measure of the size of effect of the impact that ICT-enhanced language learning had on learner achievement in reading skills. This was, therefore, determined through the calculation of effect size.

\section{Effect size analysis of significance of potential impact of technologically enhanced language learning on reading skills}

While the difference-in-differences provided a reliable estimate of the impact of technologically enhanced language learning on reading skills, and the t-test measured the significance, the effect size was used to determine how much on an effect technologically enhanced language learning had on reading skills. This was determined by calculating the Cohen's $d$ value based on the respective average post-test reading skills scores for both the test and control groups.

This resulted in an effect size value of $d=1.62$, which was classified as an large effect, as it was above the Cohen's effect size arbitrary value of 1.0 for a large effect. With this result, it was necessary to reject the null hypothesis for the study that stated "there is no statistically significant difference in achievement in English language reading skills between students taught using ICT and those not taught using ICT", and accept the alternate hypothesis that "there is a statistically significant difference in achievement in English language reading skills between students taught using ICT and those not taught using ICT".

These study findings are in agreement with various other study findings that have been conducted before to determine whether the use of technology in language learning results in significant differences between learners who learnt reading skills using technology and those that did not. For instance, a study conducted by Tri and Nguyen (2014) observed that the use of classroom technology in learning resulted in a significant increase in performance in reading skills tests over those that did not. Spiezia (2010) also found that the use of technology improved student achievement in the classroom; in that the frequency of exposure to classroom technology was directly proportional to the learners' level of achievement. While achievement was significant for those in technologically improved environments, it was also noted that the use of such classroom technology improved the learners' retention capabilities (Ramirez, 2012).

These study findings, taken into consideration alongside the study findings of the current study, work towards supporting the adoption of the alternate hypothesis for this study, that there is a significant difference in achievement in reading skills between learners taught using technologically enhanced language learning and those not taught using technologically enhanced language learning. 


\section{Conclusion}

The objective of this study was to determine the potential impact of technologically enhanced language learning on learner achievement in reading skills. The study therefore tested the null hypothesis that, there is no significant difference in achievement in English reading skills between learners taught using technologically enhanced language learning and those not taught with technologically enhanced language learning. The hypothesis was tested among secondary school English language learners in Nakuru County in four schools. The first measure used was the difference-in-differences, which was used to determine the reliable measure of difference between learners who learnt reading skills using technologically enhanced language learning and those who did not. This determined the difference in differences score at 0.7082 , which indicated that the experiment group performed better than the control group. The study also used the independent $t$-test, which was used todetermine the measure of the significance of the difference in performance between the experimental and the control groups.

This resulted in a $t$ value of $t=-12.807$, which also resulted in a $p$ value of $p=.000$, which was less than the 0.05 threshold for accepting the null hypothesis. The t-test, therefore, indicated that there was sufficient evidence to reject the null hypothesis, $\mathrm{H}_{0}$, that there is no significant difference in achievement in English reading skills between learners taught using technologically enhanced language learning and those not taught with technologically enhanced language learning; and accept the alternate hypothesis, $\mathrm{H}_{\mathrm{a}}$, that there was a significant difference in achievement in English reading skills between learners taught using technologically enhanced language learning and those not taught with technologically enhanced language learning.

In order to also determine the magnitude of the impact that technologically enhanced language learning had on learner achievement in English language reading skills, the study made use of the effect size, using the Cohen's d method. This resulted in a value of 1.60, which, according to Cohen's criteria, is quantified as a large effect.

With these statistical procedures, the null hypothesis, $\mathrm{H}_{0}$, that there is no significant difference in achievement in English reading skills between learners taught using technologically enhanced language learning and those not taught with technologically enhanced language learning; was rejected. Instead, the alternate hypothesis, $\mathrm{H}_{\mathrm{a}}$, that there was a significant difference in achievement in English reading skills between learners taught using technologically enhanced language learning and those not taught with technologically enhanced language learning, was accepted.

From this study, it was concluded that the use of TELL in learning English language reading skills led to better performance in the reading skills than learning English language reading skills without the use of TELL. This implied that, in order to improve learners' English language reading skills, the use of TELL in teaching will be more beneficial to the learners' achievement than the sole use of traditional textbook met

\section{Recommendations}

Based on the results of this study, the following recommendations are therefore proposed;

i. The government of Kenya should ensure that schools have achieved threshold minimum ICT infrastructure capabilities before the introduction of technologically enhanced learning. This will involve conducting an ICT-preparedness in the schools to determine the ICT infrastructure capability levels of Kenyan secondary schools. It will also be helpful in determining the level of ICT preparedness of Kenyan teachers for ICTbased learning. This will ensure that technologically enhanced learning has a stable and reliable platform from which it can be efficiently implemented, in order to achieve optimum effectiveness.

ii. The government should also ensure that teacher training significantly involves educational and classroom ICT training. This will be essential in helping teachers employ classroom ICT infrastructure effectively, as well as enabling them to prepare adequately for their classes.

iii. The government, in conjunction with educational content developers, educational ICT experts and teachers, should work towards developing learner-relevant classroom ICT content for subjects taught in schools. This will work towards increasing the uptake and interest of ICT-based learning among learners, with the main objective of enhancing motivation to learn, and therefore increasing effectiveness of technologically enhanced learning.

iv. As key stakeholders in education, guardians of the learners should be sensitised on the features and importance of technologically enhanced learning, that they may have an understanding of what the learners are exposed to in the learning process.

v. It is also imperative that the learners, who are the main raison d'être for technologically enhanced learning, be sensitised on the potential introduction of technologically enhanced learning, and also be sufficiently prepared for it. This will be essential in helping them fully understand what is expected of them with the introduction of technologically enhanced learning. 


\section{References}

[1]. Alexander, C. (2007). A case study of English language teaching using the Internet in Intercollege's language laboratory. The International Journal of Technology, Knowledge and Society, (3), 1-15.

[2]. Balanskat A. \&Blamire R. (2006): The ICT Impact Report Retrieved from http://insight.eun.org/shared/data/pdf/impact_study.pdf

[3]. Evoh, C. (2007). Policy networks and the transformation of secondary eucation through ICTs in Africa: The prospects and challenges of the NEPAD e-Schools initiative. International Journal of Education and Development using ICT [Online], 3(1)

[4]. Hu, G. (2002). English Language Teaching in The People's Republic of China: China Country Report. Singapore: National Insitute of Education, Nanyang Technological University.

[5]. Mdlongwa T. (2012). "Information and Communication Technology (ICT) as a Means of Enhancing Education in Schools in South Africa: Challenges, Benefits and Recommendations" in Africa Institute of South Africa Briefing NO 80 August 2012.

[6]. Ramirez, L. (2012). "Why Use Web 2.0 Tools With ELLs?” in The Best of Corwin: Educational Technology for School Leaders, Corwin.

[7]. Republic of Kenya (2012).Sessional Paper No. 12 of 2012: The Kenya National Vision 2030 Development Plan. Nairobi: Government Printer.

[8]. Spiezia, V. (2010). "Does Computer Use Increase Educational Achievements? Student-level Evidence from PISA". in OECD Journal: Economic Studies, Vol. 2010

[9]. Tri, D.H., \& Nguyen, T.H.M. (2014). "An exploratory study of ICT use In English language learning among EFL university students." in Teaching English with Technology, 14(4), 32-46.

[10]. United Nations Educational, Scientific and Cultural Organization (UNESCO) (2008).ICT Competency Standards for Teachers. United Kingdom.

[11]. Zamani, R. (2014) The Effects of Technology-Enhanced on Second Language Learning. Iran: Tabriz University. 